then perhaps one could use an antidiarrhoeal drug, such as Lomotil, though only with caution. This is because, in our experience, it is not possible to predict what dose will be toxic in children.

Both Dr Karan and Dr Limaye emphasise that in our cases severity of the symptoms was related to the dose ingested, and they also imply that symptoms only occur above a recommended therapeutic dose $0.25 \mathrm{mg} / \mathrm{kg}$ a day. But they fail to observe that on the contrary the figures for the lower limit of the ingested dose (mild, $0.62 \mathrm{mg} / \mathrm{kg}$; moderate, $0.25 \mathrm{mg} / \mathrm{kg}$; and severe, $0.77 \mathrm{mg} / \mathrm{kg}$ ) did not correlate with the severity of symptoms. We suggest that if it is necessary to use Lomotil the prescribing doctor should take cognisance of the risks.

K. M. Goel Royal Hospital for Sick Children, Yorkhill, Glasgow G3 8SJ

\section{Infantile cortical hyperostosis with raised immunoglobulins}

Sir,

Ramchander and Ramkissoon (Archives, 1978, 53, 426) drew attention to the IgA and IgM levels in 2 cases of infantile cortical hyperostosis (Roske-de Toni-Caffey syndrome). They said that a virus infection during intrauterine or neonatal life might be the cause of this disorder.

I know 2 Italian families in which this disease was diagnosed in two generations: in the first family, in the mother and her son; in the other family, the father, the daughter, and the father's first-cousin all had the disease (Duillo and Cerruti Mainardi, 1969). A few months ago another girl was born in the second family, and she shows the same disorder at age 8 weeks.

These cases, as do many other familial ones in the literature, support de Toni's hypothesis (de Toni, 1943) that genetic factors may play a role in the aetiology of this mysterious disease.

\section{References}

de Toni, G. (1943). Una nuova malattia dell' apparato osseo: la poliosteopatia deformante connatale regressiva. Policlinico Infantile, 11, 201-232.

Duillo, M. T., and Cerruti Mainardi, P. (1969). Sulla familiarità della osteopatia tipo Roske-de Toni-Caffey. II Lattante, 40, 706-731.

P. Cerruti Mainardi Divisione di Pediatria, Ospedale S. Andrea, 13100 Vercelli, Italy

\section{Polyarthritis associated with Wilson's disease}

Sir,

A 14-year-old boy was admitted to hospital in August 1978 with an acute attack of polyarthritis which he had had for one day, and which affected both knees and elbows.
There was no history of sore throat, and the family history was unremarkable. On examination he was pale, and the affected joints showed effusion with tenderness and heat. Small spider telangiectases were present over the upper sternum, and both spleen and liver were slightly enlarged. Slit-lamp examination showed Kayser Fleischer rings in both corneae.

Full blood picture, ESR, urine analysis, liver function tests, ECG, serum urate, $\mathrm{Hb}$ electrophoresis, C-reactive protein, latex-fixation test, throat swab culture, lupus erythematosus phenomenon, were all negative. ASO titre, $333 \mathrm{IU} / \mathrm{ml}$. Percutaneous liver needle biospy showed fatty changes. Serum copper $77.96 \mu \mathrm{g} / 100 \mathrm{ml}(12 \mu \mathrm{mol} / \mathrm{l})$, serum caeruloplasmin $105 \mathrm{mg} / 1(10.5 \mathrm{mg} / 100 \mathrm{ml})$, urinary copper $261 \mu \mathrm{g} / 24 \mathrm{~h}(4.09 \mu \mathrm{mol} / 24 \mathrm{~h})$.

The boy subsequently developed two further attacks of polyarthritis during the next 2 months; the findings and investigations then were similar with ASO titre 166 and $250 \mathrm{IU} / \mathrm{ml}$.

He responded well to paracetamol initially, and was then put on D-penicillamine, when he remained well until last seen in June 1979.

The association of polyarthritis with Wilson's disease has not been previously reported, and may have been coincidental, but slit-lamp examination of atypical cases of arthritis in children would be prudent.

Salim N. Bakos Department of Medicine and Paediatrics, Ports General Hospital, Maqil, Basrah, Iraq

\section{Sodium valproate, pregnancy, and neonatal hyperglycinaemia}

Sir,

It has been demonstrated that sodium valproate (SV) crosses the placenta freely and that maternal serum levels will reflect fetal serum levels (Archives, 1979, 54, 240). The SV concentration in the serum of a neonate was of the same order as that of the mother's at delivery, but fell to insignificant levels by 5 days and was undetectable at 29 days. As this child appeared healthy, it was concluded that the use of SV in pregnancy was safe.

On the other hand, administration of SV is known to cause hyperglycinaemia and hyperglycinuria in patients suffering from epilepsy (Jaeken et al., 1977; Kamoun and Parvy, 1978; Similä et al., 1979). In experiments on animals it has been shown that the rate of influx of glycine and other amino-acids into the brain is higher in the newborn period than later in life (Seta et al., 1972; Banos et al., 1978). In addition, high concentrations of glycine, which are found in nonketotic hyperglycinaemia and many organic acidaemias, are associated with severe impairment of neuronal function, and therefore a high plasma level of glycine during early postnatal life may be a risk factor (Tanaka, 1975; von Wendt et al., 1978). Therefore, we monitored the clinical state and the levels of plasma glycine and serum SV postnatally in 2 neonates; in both, the mothers had received SV treatment during pregnancy. 


\section{Case 1}

A 25-year-old woman, II para, in whom epilepsy had been diagnosed in 1972, had taken SV since March 1977. Throughout the pregnancy her dosage was SV 1350 $\mathrm{mg} /$ day and phenytoin $450 \mathrm{mg} /$ day divided in 3 doses.

In spite of therapeutic serum concentrations of these two drugs, she had had several major convulsions during early pregnancy. Delivery took place at term, the healthy boy (weight $3440 \mathrm{~g}$, Apgar score 9/10) did not show any abnormalities; growth and development during the first year of life were normal as was the EEG.

\section{Case 2}

A 24-year-old woman, III para, who had suffered from epilepsy since 1968, was started on SV in January 1978 (4 months before conception). During pregnancy she was well controlled taking SV $1200 \mathrm{mg} /$ day, phenytoin $400 \mathrm{mg} / \mathrm{day}$, carbamazepine $600 \mathrm{mg} / \mathrm{day}$, and clonazepam $1 \mathrm{mg} /$ day. A healthy girl, weighing $4000 \mathrm{~g}$ was born at term. The Apgar score was 9/9, the initial EEG and development during the first 2 months were normal.

The serum level of SV was measured in the mothers at delivery and in the neonates at birth and repeatedly postnatally. At birth, SV levels were 220 and $110 \mu \mathrm{mol} / 1$ in the neonates, and 200 and $210 \mu \mathrm{mol} / \mathrm{l}$ in the mothers, but fell to insignificant concentrations by 5 days and were undetectable at 9 days (Figure).

The plasma concentration of glycine rose markedly during the first postnatal day, the highest levels being 665 and $605 \mu \mathrm{mol} / \mathrm{l}$. These values differed very significantly from controls (Figure).

From these 2 case histories it is concluded that the use of SV in the last trimester of pregnancy induces a transient secondary hyperglycinaemia in the neonatal period, although the plasma glycine concentrations are clearly lower than in nonketotic hyperglycinaemia or organic acidaemia associated with hyperglycinaemia (Tanaka, 1975; von Wendt et al., 1978). As these infants show normal psychomotor development, it is evident that this moderate rise of glycine concentration does not impair

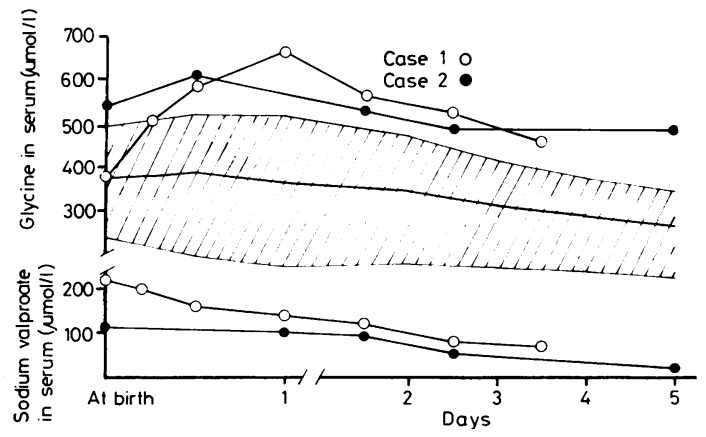

Figure Glycine (upper part) and sodium valproate (lower part) in plasma and serum respectively in 2 newborn babies during the first 5 postnatal days. Normal range of postnatal glycine levels in plasma (mean $\pm S D, n=10$ ) is shown by shaded area. the development of the CNS. However, it should be borne in mind that treatment with SV during pregnancy can cause a false-positive finding in metabolic screening for aminoacidaemias in newborn babies.

\section{References}

Banos, G., Daniel, P. M., and Pratt, O. E. (1978). The effect of age upon the entry of some amino acids into the brain, and their incorporation into cerebral protein. Developmental Medicine and Child Neurology, 20, 335-346.

Jaeken, J., Corbeel, L., Casaer, P., Carchon, H., Eggermont, E., and Eeckels, R. (1977). Letter: Dipropylacetate (valproate) and glycine metabolism. Lancet, 2, 617.

Kamoun, P., and Parvy, P. 1978). Effect du n-dipropyl acétate sur l'elimination urinaire des acides aminés. Helvetica paediatrica acta, 33, 379-383.

Seta, K., Sershen, H., and Lajtha, A. (1972). Cerebral amino acid uptake in vivo in newborn mice. Brain Research, 47, 415-425.

Similä, S., von Wendt, L., Linna, S-L., Saukkonen, A-L, and Huhtaniemi, I. (1979). Dipropylacetate and hyperglycinemia. Neuropaediatrie, 10, 158-160.

Tanaka, K. (1975). Disorders of organic acid metabolism. Biological Brain Dysfunction, 3, 145-215.

von Wendt, L., Similä, S., Hirvasniemi, A., and Suvanto, E. (1978). Altered levels of various amino acids in blood plasma and cerebrospinal fluid of patients with nonketotic hyperglycinemia. Neuropaediatrie, 9, 360-368.

S. Similä, L. von Wendt, A-L. HARTIKAINEN-Sorri, P. KÄÄPÄ, AND A-L. SAUKKONEN Departments of Paediatrics, and Gynaecology and Obstetrics, University of Oulu, 90220 Oulu 22, Finland

\section{Neutropenia during sodium valproate treatment}

Sir,

Thrombocytopenia is a well-known side effect of sodium valproate (dipropylacetic acid) treatment (Winfield et al., 1976; Raworth and Birchall, 1978; Sandler et al., 1978). As far as we know, neutropenia has not been documented during valproate medication. Recently we treated a 3 -month-old boy with sodium valproate $(40 \mathrm{mg} / \mathrm{kg}$ per day) because of postanoxaemic convulsions. No other drugs were given. Total blood neutrophils decreased steadily from pretreatment values between $3 \cdot 5$ and $5.4 \times 10^{9} / 1$ to a value as low as $0.460 \times 10^{9} / 1$ during the next 2 months. Valproate was stopped and total neutrophil count promptly increased to $2.0 \times 10^{\circ} / 1$ within 14 days and to pretreatment values within a few weeks. Thrombocytes remained within normal limits. Erythrocyte count did not change. Because of the fragile condition of the infant a bone marrow puncture was not performed. Antibodies against thrombocytes have been shown in valproate-induced thrombocytopenia (Sandler et al., 1978); in our patient immunofluorescence studies at the time of the lowest neutrophil count failed to demonstrate antibodies against granulocytes. Thrombocytopenia, and now neutropenia, as well as hyperglycinaemia (Jaeken et al., 1977; Kamoun et al., 1977), normal glycinorrhachia (Jaeken et al., 1977), and ketonuria (Simon and Penry, 